PENGEMBANGAN KURIKULUM BERBASIS KWU DI PRODI D3 TATA BUSANA TI UM JURUSAN TEKNOLOGI INDUSTRI - FT- UM

UNTUK MENEKAN PENGANGGURAN INTELEKTUAL

\author{
MAKALAH \\ Disampaikan dalam Seminar Nasional \\ PADA KONVENSI NASIONAL V APTEKINDO
}

Pada Tanggal 29 April -2 Mei 2010

di Universitas Pendidikan Ganesha

Oleh:

Agus Hery Supadmi Irianti

Dosen Teknologi Industri FT-UM

Telp 0341-585582, HP: 081233594878 


\title{
PENGEMBANGAN KURIKULUM BERBASIS KWU DI PRODI D3 TATA BUSANA TI UM JURUSAN TEKNOLOGI INDUSTRI - FT- UM UNTUK MENEKAN PENGANGGURAN INTELEKTUAL
}

\author{
Oleh \\ Agus Hery Supadmi Irianti \\ Jurusan TI-Fakultas Teknik Universitas Negeri Malang
}

\begin{abstract}
Abstrak: Data Badan Pusat Statistik (BPS) menyebutkan, pada Februari 2009, tingkat pengangguran terbuka di Indonesia mencapai 9,26 juta atau 8,14 persen dari total angkatan kerja. Angka ini turun dibanding Agustus 2008 sebesar 8,39 persen dan Februari 2008 sebesar 8,46 persen. Meskipun ditengarai turun, angka pengangguran masih tetap tinggi karena bertengger di kisaran 8 persen. (Market Review / Ekonomi / Jumat, 18 Desember 2009) Artinya pengangguran di Indonesia masih saja tinggi walaupun sempat mengalami penurunan angka pengangguran tersebut ( perhatikan perbedaan dengan data Tahun 2006 Data tersebut menunjukkan bahwa perguruan tinggi juga memberikan andil pada tingginya angka pengangguran di Indonesia. Telah kita ketahui bersama bahwa lontaran kritik terhadap system pendidikan yang mengatakan bahwa perluasan kesempatan belajar cenderung menyebabkan bertambahnya pengangguran tenaga terdidik dari pada bertambahnya tenaga produktif yang sesuai dengan kebutuhan lapangan kerja. Bagaimanakah keterkaitan antara kualitas pendidikan dengan kurikulum?. Pendidikan yang berkualitas akan menghasilkan lulusan yang berkualitas, dan lulusan berkualitas adalah lulusan yang memiliki daya saing yang tinggi dan siap menjadi tenaga kerja yang professional, sedangkan tenaga kerja professional yang dimaksud disini adalah lulusannya, yaitu lulusan yang memiliki ketrampilan melalui pendidikan formal dan diakui keahliannya dan kompeten dibidangnya. Oleh sebab itu Kurikulum pendidikan memiliki arti penting yang tidak dapat diabaikan begitu saja. agar mampu menekan jumlah pengangguran intelektual maka diperlukan upaya penyeimbangan antara suplly dan demand melalui [engembangan kurikulum dan konsolidasi membangun kurikulum yang dibutuhkan dengan menyesuaikan kebutuhan pasar. Untuk mereduksi pengangguran, bisa dilakukan dengan kewirausahaan. Menumbuhkembangkan kewirausahaan bisa dilakukan dengan pemetaan dan identifikasi populasi calon wirausahawan dan wirausaha produktif
\end{abstract}

\section{PENDAHULUAN}

\section{Tingkat pengangguran di Indonesia}

Saat ini angka pengangguran di Indonesia masih cukup tinggi. Hal ini terlihat dari masih banyaknya angkatan kerja yang berjubel mencari kerja di sebuah acara bursa 
tenaga kerja yang digelar di Salah satu kota, baru-baru ini. Meski pemerintah mengklaim telah menurunkan tingkat pengangguran, tetap saja angka pengangguran belum beranjak turun dari angka delapan persen. Salah satu bursa tenaga kerja yang digelar di Thamrin City, Jakarta Pusat, baru-baru ini dipenuhi sekitar 2.000 pencari kerja untuk melamar 500 lowongan di 46 perusahaan. Para pencari kerja berasal dari berbagai wilayah di sekitar Jakarta. Posisi pekerjaan yang ditawarkan beragam, dari mulai pekerjaan di hotel, rumah sakit, retail, pelayaran, bahkan lowongan menjadi tenaga kerja Indonesia di luar negeri. Kondisi ini juga terjadi di kota-kota lainnya tidak hanya di Jakarta saja. Data Badan Pusat Statistik (BPS) menyebutkan, pada Februari 2009, tingkat pengangguran terbuka di Indonesia mencapai 9,26 juta atau 8,14 persen dari total angkatan kerja. Angka ini turun dibanding Agustus 2008 sebesar 8,39 persen dan Februari 2008 sebesar 8,46 persen. Meskipun ditengarai turun, angka pengangguran masih tetap tinggi karena bertengger di kisaran 8 persen. (Market Review / Ekonomi / Jumat, 18 Desember 2009) Artinya pengangguran di Indonesia masih saja tinggi walaupun sempat mengalami penurunan angka pengangguran tersebut ( perhatikan perbedaan dengan data Tahun 2006 di bawah ini).

Tabel 1. Angka Pengangguran ditinjau dari Umur

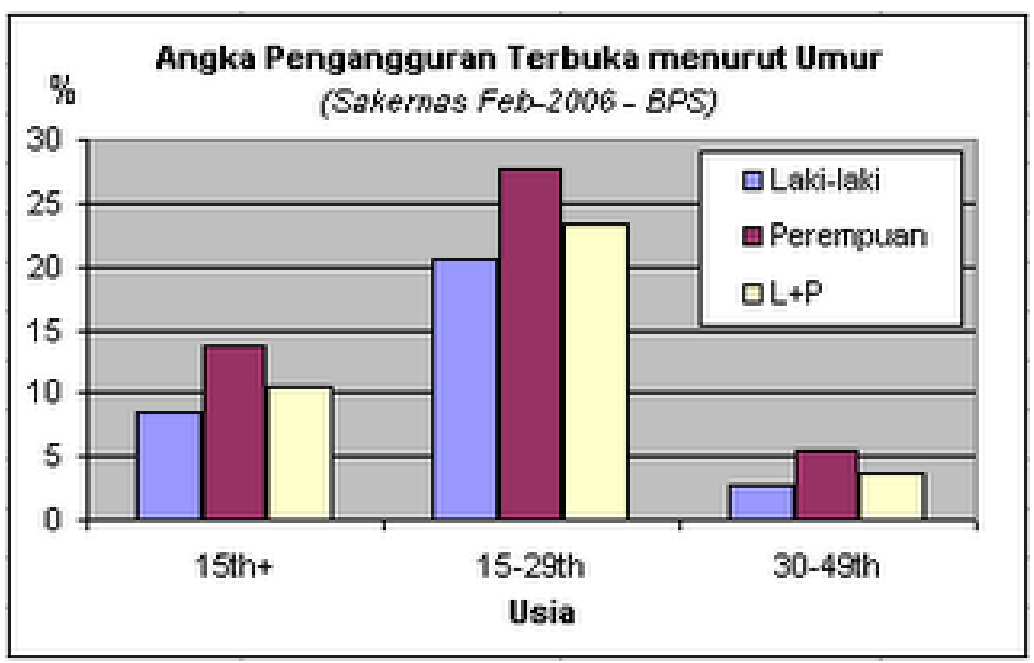

Sumber:Sakernas 
Tabel 2. Angka Pengangguran ditinjau dari Jenis Kelamin
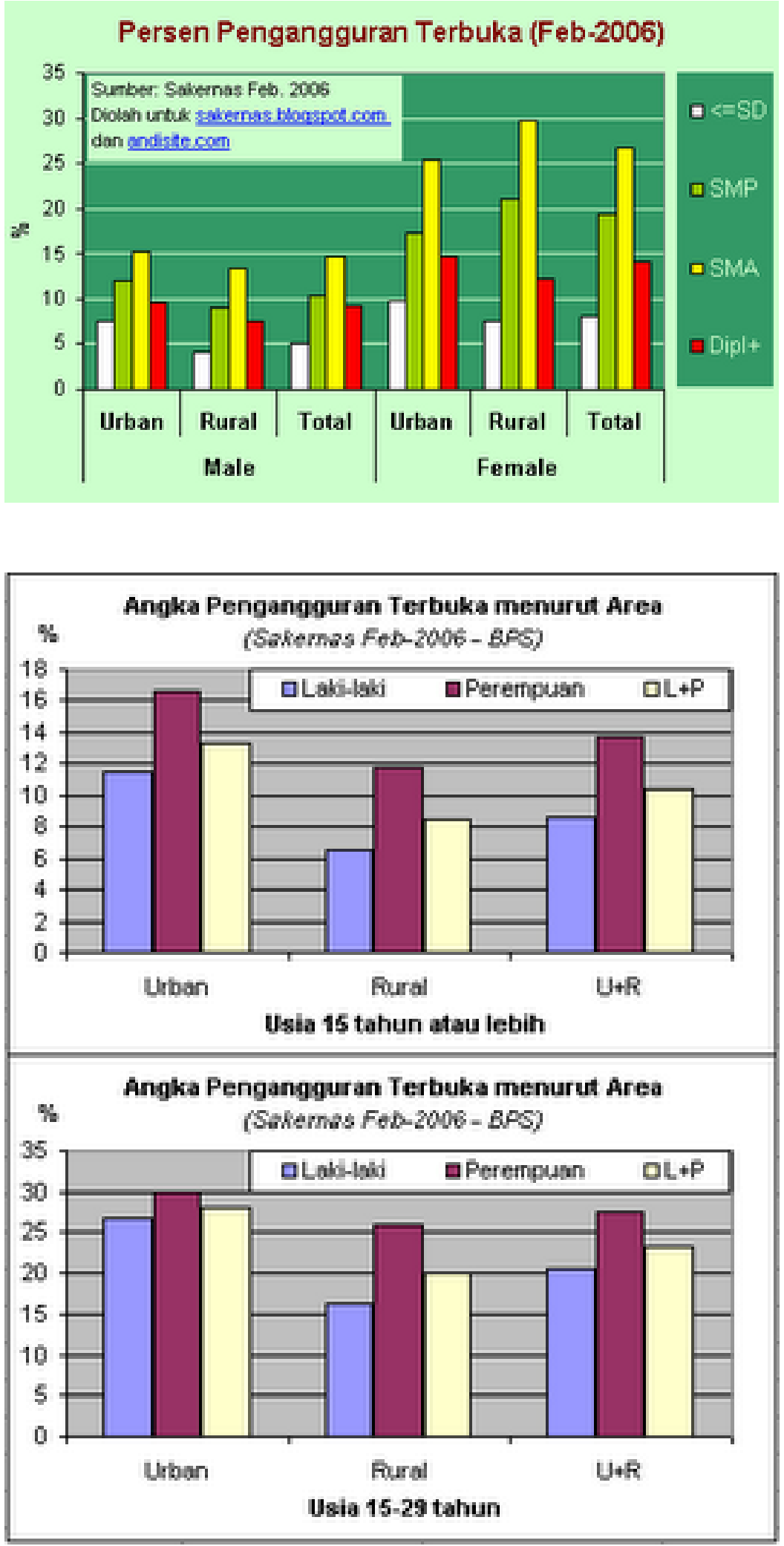
Berdasarkan data Badan Pusat Statistik (BPS), pengangguran berpendidikan tinggi, baik diploma maupun sarjana, selama periode 2004-2009 bertambah 529.662 jiwa. Pada 2004 jumlahnya 585.358 orang dan 2009 lalu bertambah menjadi 1.115.020 jiwa. Jika di rata-rata, setiap tahun pengangguran berpendidikan tinggi bertambah hampir 106.000 jiwa. Data pada 2008 tercatat sebanyak 23,80\% penganggur adalah mereka yang memiliki ijazah pendidikan tinggi, baik diploma atau sarjana. Angka itu naik menjadi $26,74 \%$ pada 2009. Data tersebut menunjukkan bahwa perguruan tinggi juga memberikan andil pada tingginya angka pengangguran di Indonesia. Telah kita ketahui bersama bahwa lontaran kritik terhadap system pendidikan yang mengatakan bahwa perluasan kesempatan belajar cenderung menyebabkan bertambahnya pengangguran tenaga terdidik dari pada bertambahnya tenaga produktif yang sesuai dengan kebutuhan lapangan kerja . Hal ini memang beralasan karena data presentasi pencari kerja terhadap angkatan kerja menurut tingkat pendidikan menunjukkan bahwa semakin tinggi persentasi tingkat pendidikan angkatan kerja, semakin tinggi persentase tingkat penganggurannya Suryadi Ace dan Tilaar H.A.R, 1993: 166)

Terkait dengan hal tersebut diatas pendidikan Tinggi sebagai pencetak tanaga kerja memiliki posisi yang strategis dan berdampak secara berantai pada seluruh aspek bidang kehidupan. Pendidikan yang unggul dapat meningkatkan mutu sumber daya manusia dan pada gilirannya dapat menentukan keunggulan bidang-bidang lainnya seperti ekonomi, polotik, social-budaya dan keamanan, karena manusia adalah pelaku utama dari seluruh aktifitas bidang-bidang. ( Sonhaji, 2004:4 ). Tingginya angka pengangguran lulusan dari perguruan tinggi karena ketiadaan semangat juang. Pembelajaran di perguruan tinggi juga tidak membuat mahasiswa dapat langsung bekerja, tapi perlu mendapatkan pelatihan. Peningkatan jumlah pengangguran terdidik mungkin akibat ketidaksesuaian antara apa yang dihasilkan (supply) dengan apa yang dibutuhkan (demand) industri. Upaya menyeimbangkan supply dan demand tenaga kerja membutuhkan kerja sama antara industri dan perguruan tinggi. Industri membutuhkan perguruan tinggi. Begitu sebaliknya, kurikulum perguruan tinggi perlu melihat arah pengembangan industri. 
Kurikulum D3 Program studi D3 Tata Busana Jurusan Teknologi Industri

Fakultas Teknik Malang, terdiri dari 51 mata kuliah dengan total sks115 dan 183 js dan , memiliki ciri kewirausahaan terbagi dalam kelompok Mata kuliah sebagai berikut,:

Tabel 4. Kelompok Mata Kuliah dalam Kurikulum D3 Prodi Tata Busana.

\begin{tabular}{|l|l|l|l|l|l|}
\hline & Kelompok Mata Kuliah & Kode MK & Jml MK & SKS & JS \\
\hline A & MK Pengembangan Kepribadian & MPK & 4 & 8 & 8 \\
\hline B & MK Keilmuan dan ketrampilan & MKK & 15 & 29 & 42 \\
\hline C & MK Keahlian Berkarya & MKB & 19 & 51 & 98 \\
\hline D & MK Perilaku berkarya & MPB & 4 & 9 & 9 \\
\hline E & MK Berkehidupan Bermasyarakat & MBB & 9 & 40 & 40 \\
\hline & Jumlah & & 51 & 115 & 183 \\
\hline
\end{tabular}

( sumber: Katalog Jurusan TI, FT UM)

Adapun kompetensi Prodi D3 Tata Busana dapat dilihat pada table berikut ini, Tabel.5. Kompetensi Prodi D3 Tata Busana Jurusan TI FT UM

\begin{tabular}{|c|c|c|}
\hline No & Kompetensi & Sub Kompetensi \\
\hline 1 & Supervisor Industri Busana & $\begin{array}{l}\text { 1. Memiliki kemampuan menggunakan alat jahit dengan } \\
\text { tepat } \\
\text { 2. Memiliki pengetahuan memilih bahan } \\
\text { 3. Memiliki kemampuan membuat desain } \\
\text { 4. Memiliki kemampuan membuat pola busana (konstruksi } \\
\text { standart). } \\
\text { 5. Memiliki kemampuan membuat pola secara grading. } \\
\text { 6. Memiliki kemampuan memotong bahan sesuai pola., } \\
\text { menjahit sesuai model, packing dan labeling } \\
\text { 7. Memiliki kemampuan menghias kain/busana } \\
\text { 8. Memiliki kemampuan membuat pelengkap busana } \\
\text { 9. Memiliki kemampuan tentang Pengetahuan dan } \\
\text { keterampilan K3 } \\
\text { 10.Memiliki kemampuan melakukan komunikasi dengan } \\
\text { baik } \\
\text { 11.Memiliki kemampuan tentang kepengawasan (supervisi) } \\
\text { pada perencanaan produksi, proses dan pengendalian } \\
\text { mutu. }\end{array}$ \\
\hline \multirow[t]{3}{*}{2} & $\begin{array}{l}\text { Pengelola Usaha } \\
\text { a Pengelola Usaha Busana } \\
\text { Modiste }\end{array}$ & $\begin{array}{l}\text { 1. Memiliki pengetahuan tentang manajemen usaha } \\
\text { 2. Memiliki kemampuan mengelola usaha busana } \\
\text { modiste/tailor }\end{array}$ \\
\hline & $\begin{array}{l}\text { b Pengelola Usaha Busana } \\
\text { Industri }\end{array}$ & $\begin{array}{l}\text { 1. Memiliki pengetahuan tentang manajemen usaha } \\
2 \text { Memiliki kemampuan mengelola usaha busana industri }\end{array}$ \\
\hline & c Pengelola Usaha Butik & $\begin{array}{l}\text { 1. Memiliki pengetahuan tentang manajemen usaha } \\
\text { 2. Memiliki kemampuan mengelola usaha busana butik }\end{array}$ \\
\hline
\end{tabular}




\begin{tabular}{|l|l|l|}
\hline 3 & Instruktur Bidang Busana & $\begin{array}{l}\text { 1. Memiliki Pengetahuan tentang busana } \\
\text { 2. Memiliki kemampuan melakukan komunikasi dengan } \\
\text { baik }\end{array}$ \\
$\begin{array}{l}\text { 3. Memiliki Kemampuan dan Ketrampilan menyampaikan } \\
\text { materi bidang busana }\end{array}$ \\
\hline
\end{tabular}

(Sumber: Kopetensi Prodi D3, Tata Busana TI)

\section{PEMBAHASAN}

Beberapa data terakhir menunjukkan indikasi mengkhawatirkan di mana pengangguran terdidik meningkat signifikan. Jumlah penganggur di kalangan terdidik sampai Februari 2009 mencapai 1,1 juta orang. Angka ini naik hampir dua kali lipat dibandingkan jumlah pengangguran terdidik pada 2004, 585.000 orang. Padahal, di saat yang sama, sebenarnya terjadi penurunan jumlah pengangguran di Indonesia secara absolut atau persentase menurut data Badan Pusat Statistik (BPS).Gejala ini perlu kita cermati. Peningkatan jumlah pengangguran terdidik mungkin akibat ketidaksesuaian antara apa yang dihasilkan (supply) dengan apa yang dibutuhkan (demand) industri. Pendidikan mempunyai kualitas tinggi apabila keluaran pendidikan dalam hal ini lulusannya mempunyai nilai bagi masyarakat yang memerlukannya. Dengan kata lain upaya yang paling efektif dalam meningkatkan Sumber Daya Manusia melalui pendidikan. Tingginya angka pengangguran lulusan dari perguruan tinggi karena ketiadaan semangat juang. Pembelajaran di perguruan tinggi juga tidak membuat mahasiswa dapat langsung bekerja, tapi perlu mendapatkan pelatihan. Peningkatan jumlah pengangguran terdidik mungkin akibat ketidaksesuaian antara apa yang dihasilkan (supply) dengan apa yang dibutuhkan (demand) industri. Upaya menyeimbangkan supply dan demand tenaga kerja membutuhkan kerja keras perguruan tinggi, untuk bertindak khususnya mencermati kurikulum perguruan tinggi barangkali perlu arah pengembanganyang relevan sehingga dapat meminimalisir angka pengangguran yang berasal dari lulusan perguruan tinggi.

Bagaimanakah keterkaitan antara kualitas pendidikan dengan kurikulum?. Pendidikan yang berkualitas akan menghasilkan lulusan yang berkualitas, dan lulusan berkualitas adalah lulusan yang memiliki daya saing yang tinggi dan siap menjadi tenaga kerja yang professional, sedangkan tenaga kerja professional yang dimaksud 
disini adalah lulusannya, yaitu lulusan yang memiliki ketrampilan melalui pendidikan formal dan diakui keahliannya dan kompeten dibidangnya. Oleh sebab itu Kurikulum pendidikan memiliki arti penting yang tidak dapat diabaikan begitu saja.

Untuk dapat mewujudkan tenaga kerja yang professional tersebut diatas maka banyak aspek yang harus dipersiapkan, seperti: Kurikulum, Metode Pembelajaran, Sumber Daya Manusia, Sarana Prasarana, Managemen dan masih banyak lagi komponen lain. Hal ini sesuai dengan Misi Pendidikan Nasional, yaitu:

1. Mewujudkan sistim dan iklim pendidikan nasional yang demokratis dan berkualitas.

2. Mewujudkan kehidupan social budaya yang berkepribadian dinamis, kreatif, dan berdaya tahan terhadap pengaruh globalisasi.

3. Meningkatkan pengamalan pengajaran agama dalam kehidupan sehari-hari.

4. Meningkatkan kualitas sumber daya manusia yang produktif, mandiri, maju dan berdaya saing, berwawasan lingkungan dan berkelanjutan.

\section{METODE}

Kurikulum sebagai salah satu aspek penting yang dapat mempengaruhi pendidikan yang unggul dapat meningkatkan mutu sumber daya manusia dan pada gilirannya dapat menentukan keunggulan bidang-bidang lainnya seperti ekonomi, polotik, social-budaya dan keamanan, karena manusia adalah pelaku utama dari seluruh aktifitas bidang-bidang tersebut, maka diperlukan Upaya menyeimbangkan supply dan demand tenaga kerja melalui :

1. Pengembangan kurikulum, antara lain:

> Melibatkan pihak industri dan instansi lain yang terkait dalam menyusun kurikulum agar terwujud sinkronisasi kurikulum dengan dunia usaha dan dunia industri

Senantiasa ditinjau kembali kontennya agar tidak ketinggalan dengan lajunya IPTEK di dunia usaha dan dunia industri.

Mengupayakan sertifikasi agar lulusannya diakui keahliannya 
2. Perguruan tinggi dapat melakukan konsolidasi untuk membangun kurikulum yang dibutuhkan demi menghasilkan SDM yang berketerampilan. Berdasarkan pemahaman ini, penyelenggaraan program S-1, vokasi, D-3, dan D-4 perlu menyesuaikan diri dengan kebutuhan pasar dan arah pengembangan industri. Sebagai contoh,strategi pengembangan Kawasan Ekonomi Khusus (KEK) yang direncanakan pemerintah juga harus didukung perguruan tinggi.

3. Untuk mereduksi pengangguran, bisa dilakukan dengan kewirausahaan. Menumbuhkembangkan kewirausahaan bisa dilakukan dengan pemetaan dan identifikasi populasi calon wirausahawan dan wirausaha produktif

\section{KESIMPULAN}

Dari uraian di atas dapat disimpulkan bahwa untuk meningkatkan kualitas lulusan agar mampu menekan jumlah pengangguran intelektual maka diperlukan upaya penyeimbangan antara suplly dan demand melalui [engembangan kurikulum dan konsolidasi membangun kurikulum yang dibutuhkan dengan menyesuaikan kebutuhan pasar. Untuk mereduksi pengangguran, bisa dilakukan dengan kewirausahaan. Menumbuhkembangkan kewirausahaan bisa dilakukan dengan pemetaan dan identifikasi populasi calon wirausahawan dan wirausaha produktif

\section{DAFTAR PUSTAKA}

Ahmad Sonhadji, 2004. Makalah Seminar Nasional: Resource Sharing antaraPendidikan tinggi dan Pendidikan Menengah dalam Meningkatkan Kualitas Lulusan. Malang: Fakultas Teknik Universitas Negeri Malang

Departemen Pendidikan dan Kebudayaan, 1997. Keterampilan Menuju 2020 Untuk Era Global. Jakarta: Laporan Satgas Pengembang an Diklat Kejuruan di Indonesia.

Depdiknas. 2003. Kurikulum SMK 2004. Jakarta: Dirjen Dikdasmen Direktorat Pendidikan Kejuruan.

HAR Tilaar, 1997. Pengembangan Sumber Daya Manusia Dalam Era Globalisasi. Jakarta: PT Gramedia Widiasarana Indonesia.

Market Review / Ekonomi / Jumat, 18 Desember 2009 


\section{FAKULTAS TEKNIK DAN KEJURUAN UNIVERSITAS PENDIDIKAN GANESHA}

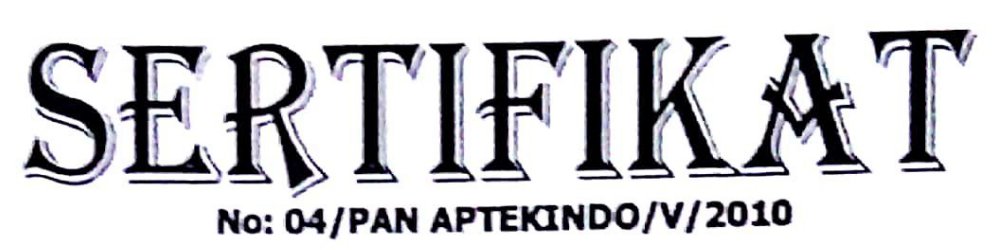

DIBERIKAN KEPADA :

\section{Agus Hery Supadmi Irianti}

Sebagai

\section{PEMAKALAH}

Dalam

\section{SEMINAR INTERNASIONAL}

\section{Peran LPTK Dalam Pengembangan Pendidikan Vokasi Di Indonesia \\ Dalam Rangka KONVENSI NASIONAL V, TEMU KARYA XVI \\ Asosiasi Pendidikan Teknologi dan Kejuruan (A.PTEKINDO) FT/FTK/FPTK-JPTK se - Indonesia di FAKULTAS TEKNIK DAN KEJURUAN UNIVERSITAS PENDIDIKAN GANESHA \\ DENPASAR, 30 APRIL 2010}

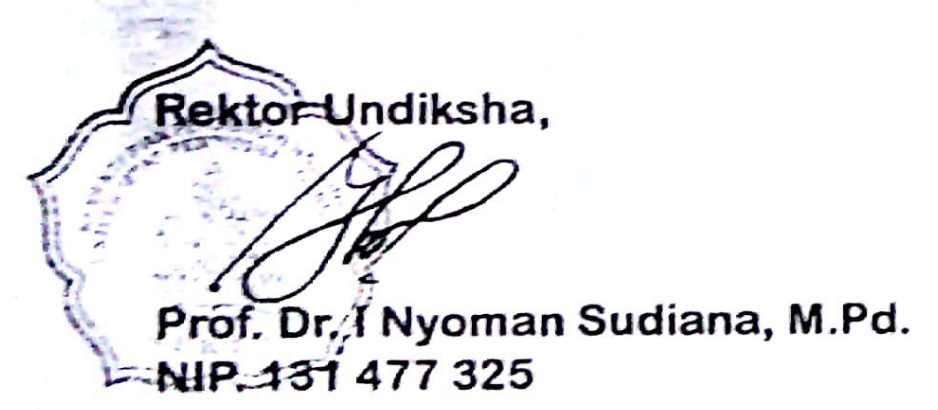

Denpasar, 30 April 2010

Ketuia Pelaksana,

Próf, Dr, I Nyoman Sudiana, M.Pd.

LNAP. 131477325

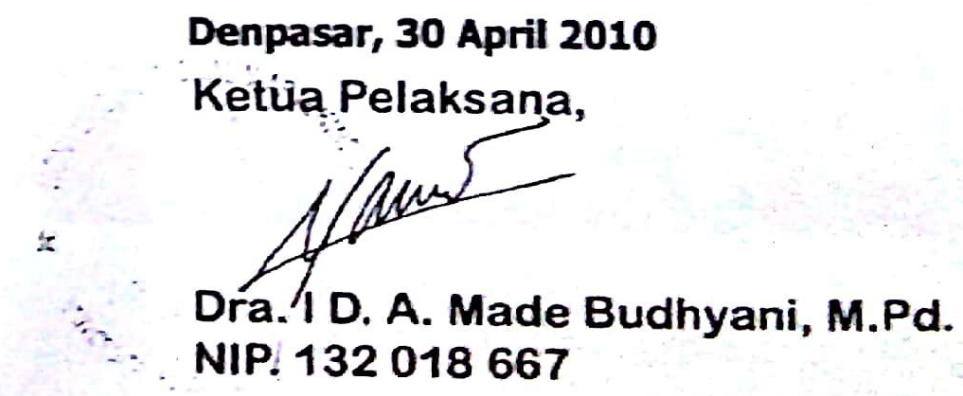

